\title{
LECTORES RETRATADOS: POLÍTICA VISUAL, ESPACIO DOMÉSTICO Y DISCURSO DE LAS PASIONES A COMIENZOS DEL SIGLO XIX
}

\author{
POR \\ Fernando Degiovanni \\ Wesleyan University
}

Entre 1830y 1836, Carlos Enrique Pellegrini (Chambery, 1800-BuenosAires, 1875) produce en Buenos Aires una de las series de retratos más vasta de la historia cultural argentina. En los más de cien trabajos que se conservan del artista, no sólo se visualizan el rostro y los cuerpos de los protagonistas de la vida porteña de comienzos del siglo XIX: se promueve también un modo de interpretar la política y la sociedad argentina de los primeros años del régimen de Rosas. Contratado en 1827 por un representante del gobierno de Rivadavia en París con el propósito de llevar a cabo obras públicas en Buenos Aires, Pellegrini llega al Río de la Plata en 1928, momento en que el presidente unitario ya ha renunciado y los federales se encuentran en el poder. Ese inesperado cambio de coyuntura política constituye, para el joven ingeniero saboyano, el punto de partida de un proyecto artístico que no figuraba en sus planes: con el objetivo de sostenerse económicamente en una ciudad dominada por el enfrentamiento faccioso y la guerra de ideas, Pellegrini se vale entonces de los elementos de dibujo que había adquirido en sus años de estudiante universitario en Europa para producir entre quinientas y ochocientas obras destinadas a retratar, en su mayor parte, las figuras de la elite posrevolucionaria porteña. ${ }^{1}$

Pero estos improvisados comienzos artísticos de Pellegrinino deben asociarse con el desarrollo de una producción carente de coherencia. Por el contrario, desde sus primeros retratos, Pellegrini introduce en Buenos Aires una manera de construir visualmente a la elite argentina que se define no sólo por el uso de parámetros iconográficos definidos, sino también por la demarcación de una serie de temas estético-ideológicos específicos que el retratista intenta promover en el ámbito de la cultura política y social porteña del primer rosismo. En este contexto, la elaboración de una extendida galería de retratos de lectores y escenas de lectura constituye uno de los rasgos más recurrentes y distintivos de su obra. En efecto, más que ninguno de los artistas que trabajaron en el Río de la Plata por esa época -Juan F. Goulu o Amadeo Gras, por ejemplo- Pellegrini hace de la

\footnotetext{
${ }^{1}$ Las opiniones de Pellegrini sobre el número total de retratos que produjo son variables (Garaño 26).
} 
representación de hombres y mujeres acompañados de libros impresos, obras manuscritas, documentos, cartas, sobres y tarjetas con mensajes y leyendas, el eje de una reflexión sobre el presente político y cultural argentino. A través del uso de artefactos verbales destinados a subrayar detalles puntuales de la personalidad del sujeto retratado -lo que Pope-Hennessy llamó la producción de "augmented portraits" (208)-, Pellegrini busca posicionarse dentro de esa gran ola de optimismo ilustrado que, iniciada en el Renacimiento, acompañó decisivamente los movimientos revolucionarios en Europa y América. De este modo, su apuesta por el retrato de lectores constituye, para el ámbito porteño, una manifestación visual de esa "metafísica del humanismo mismo" (95) que Garrett Stewart definió como característica definitoria del género.

\section{“El pequeño Horace Vernet de Buenos Aires"}

Sin formación específica en el empleo de materiales ligados tradicionalmente a la producción de retratos -preferirá el lápiz, la tinta china y la acuarela sobre el óleo, el grabado o el pastel-, Pellegrini no ignora, sin embargo, las escuelas y referentes más destacados del mundo artístico francés de su época. En su modo de enfrentar el retrato hay resonancias de los pintores neoclásicos más destacados de fines del siglo XVIII y comienzos del siglo XIX. Su conocimiento de los trabajos de Jacques Louis David es evidente; Eduardo Schiaffino ha insistido por su parte en la relación de su obra con la de Jean Auguste Dominique Ingres (32-34). Finalmente, están las propias declaraciones de Pellegrini: el hecho de que le señale a su hermano Jean Claude en una carta del 27 de mayo de 1831 que se ha convertido en "el pequeño Horace Vernet de Buenos Aires" (33) constituye una indicación de que también estaba familiarizado con la obra de los primeros románticos. ${ }^{2}$

En principio, los términos de la comparación con Vernet deben buscarse menos en aspectos técnicos y formales que en razones económicas y políticas. En efecto, el trazo rápido y libre, el uso de colores contrastantes, la confusión y acumulación desordenada de elementos que caracteriza las obras de Vernet son claramente ajenos a la práctica artística de Pellegrini, cuyos retratos muestran una clara organización espacial y escasa variación cromática. Por su lado, la pintura monumental de tema histórico, característica de Vernet, también está fuera del interés de Pellegrini. En este contexto, la referencia de Pellegrini a su modelo europeo parece querer subrayar otro aspecto: la facilidad y fecundidad de la producción de Vernet, algo por lo que el artista romántico era ampliamente conocido en su época. En la citada carta a su hermano,

2 Todas las declaraciones de Pellegrini se citan a partir del libro de Alma N. Marani, Carlos E. Pellegrini, que contiene la transcripción de su correspondencia y escritos. Se traducen al castellano los textos de Pellegrini escritos originalmente en francés. Indico en cada caso la página correspondiente al libro de Marani.

Revista Iberoamericana, Vol. LXXXII, Núm. 257, Octubre-Diciembre 2016, 721-742 ISSN 0034-9631 (Impreso)

ISSN 2154-4794 (Electrónico) 
Pellegrini destaca además los provechosos réditos económicos y el prestigio creciente que le están dando sus retratos porteños: según indica, "el cabo de mi pincel es la varita mágica que me produce estos tesoros" (33).

Pero tampoco debe descartarse aquí una referencia velada a la orientación estéticoideológica de la obra de Vernet: en el momento en que Pellegrini parte para Buenos Aires en 1828, las pinturas de Vernet son interpretadas en París como un manifiesto de la resistencia liberal a la opresión que supone la restauración borbónica. Bonapartista acérrimo, Vernet había hecho por entonces de su taller el epicentro de las reuniones de los partidarios de Napoleón. De hecho, sus pinturas de batallas históricas fueron rechazadas por el gobierno de la restauración borbónica, pero gozaron de un prolongado y unánime clamor del público, que reconocía en él a un patriota (MacClintock 80-81). La adhesión de Pellegrini a la política napoleónica había sido clara desde el momento de su ingreso a la Universidad de Turín en 1819, donde participó en las luchas contra la monarquía conservadora piamontesa, lo que le valió el exilio en Francia. Según Marani, "la Universidad de Torino tenía fama de contar en su claustro con hombres ilustrados y progresistas, al punto de suscitar sospechas tanto en Vittorio Emanuele I como en Carlo Felice" (12). Partidario de las ideas de libertad y nacionalismo, Pellegrini abrazó allí los ideales carbonarios de los piamonteses que "clamaron por un estatuto y por la autonomía frente a las continuas injerencias de Austria” (13), así como por una mejora en las condiciones sociales. Muchos años después, Pellegrini reflexionaría sobre su participación en el alzamiento contra la monarquía conservadora en estos términos: “en el año [18]21 ofrecimos nuestra vida en el altar de su independencia [de Italia], alzando y conservando hasta la última hora la bandera de guerra contra los opresores" (13).

Estos ideales liberales explican la sintonía inmediata de Pellegrini con las ideas reformistas de Rivadavia y sus partidarios. Con todo, la situación de imprevisibilidad económica en que lo puso el hecho de que los unitarios se encontraran fuera del gobierno cuando llegó al Río de la Plata, hizo que decidiera no oponerse abiertamente a los gobernantes federales. Temeroso de la guerra civil, al principio tuvo confianza, de hecho, en que el poder de Rosas pudiera pacificar el país. Pero es evidente que sus relaciones con el líder federal fueron puntuales, y por razones de conveniencia. Se sabe, en este sentido, que retrató a algunos miembros del sector federal a pedido de Rosas. Pero también existe sólida evidencia de que se hallaba lejos de los círculos rosistas y de sus ideales políticos y culturales. No sólo su lucha y exilio en Europa por la defensa de los principios liberales corrobora esta visión, sino también numerosos datos de su vida pública en Buenos Aires. Además de su cercana amistad con Rivadavia cuando éste se hallaba en el país, el hecho de que Pellegrini se atreviera a visitarlo cuando regresó a Buenos Aires en 1834 muestra su lealtad al expresidente a pesar del clima político adverso. En efecto, Pellegrini se contó entre las tres personas que, en medio de guardias que daban vivas a Rosas, acompañaron a Rivadavia al barco que lo llevó de regreso a Europa cuando fue forzado al exilio definitivo (Marani 46). Por último, en

Revista Iberoamericana, Vol. LXXXII, Núm. 257, Octubre-Diciembre 2016, 721-742 ISSN 0034-9631 (Impreso)

ISSN 2154-4794 (Electrónico) 
1857, cuando los restos de Rivadavia volvieron al país, Pellegrini compuso el poema “Aux manes de Rivadavia", destinado a exaltar la visión progresista del expresidente, texto que amplió para uso escolar en 1874.

En el plano personal, Lucio V. Mansilla escribió en Mis memorias que el fracaso del matrimonio de Pellegrini con su madre se debió a reservas ideológicas de una y otra parte: “¿Renunció [Pellegrini] a la hermana de [Rosas] -dice Mansilla- porque presintió o columbró el porvenir y temió ligarse a su familia, o ésta opuso trabas a sus pretensiones porque el sello de hombre de ciencia, extranjero por añadidura, reclutado por Rivadavia, considerado cuasi ateo, tenía que ser mirado como un caballo de Troya introducido en sus filas?" (54). Por último, cuando ya sin clientes para sus retratos, debido a la emigración de la elite, y hostilizado por su carácter de extranjero durante el bloqueo anglofrancés, decidió invertir sus ahorros en el campo, sintió en su residencia rural los beneficios de hallarse alejado del espacio más inmediato de influencia de Rosas (Marani 47). Pero es en su galería de retratos donde se encuentra, sin duda, el documento más ostensible de su crítica a la política rosista. Así como la obra de Vernet había estado dedicada a defender el régimen napoleónico desplazado, en Pellegrini también puede hallarse un decidido compromiso con la ya derrotada política rivadaviana.

\section{UNA PEDAGOGÍA VISUAL DOMÉSTICA}

Participante activo de las tertulias donde se discutía el poder de Rosas, Pellegrini introdujo desde su llegada una transformación sustancial en los modos de circulación y consumo de la imagen en Buenos Aires: a diferencia de los retratos coloniales, pintados al óleo o difundidos en grabados, y destinados sobre todo a ocupar espacios institucionales y públicos - preferentemente iglesias y edificios de gobierno- con Pellegrini cobra fuerza por primera vez la producción de representaciones realizadas para el ámbito doméstico y la contemplación privada. La transformación del sujeto de la representación es otro dato significativo en este contexto: no se trata ya de retratos de reyes, funcionarios virreinales o miembros del clero en los que se muestran emblemas honoríficos y dinásticos, sino de miembros de una elite republicana que aparece retratada sin marcadores simbólicos de privilegio y autoridad heredada: en lugar de títulos nobiliarios o religiosos, los miembros de la elite se muestran ahora rodeados de libros, documentos y artículos suntuarios que subrayan su conexión con el conocimiento y la ilustración.

Esta nueva manera de representar rostros y cuerpos coincide con el momento en que Rosas introduce cambios profundos en el clima político, social y cultural del país: frente al incremento de la violencia, así como en la disminución de las posibilidades de disenso en el debate letrado, se genera un movimiento de oposición ideológica que tiene lugar menos en el ámbito de la calle y en las instituciones públicas que en el espacio semiprivado de las librerías, gabinetes de lectura y salones literarios que habían

Revista Iberoamericana, Vol. LXXXII, Núm. 257, Octubre-Diciembre 2016, $721-742$ ISSN 0034-9631 (Impreso)

ISSN 2154-4794 (Electrónico) 
florecido desde la década de 1820. En este contexto, los salones y despachos de las casas porteñas ocupan también un lugar de privilegio en la circulación y el debate de ideas. Es en esas reuniones sociales donde la presencia de textos e imágenes define un sentido específico de comunidad. Como ha señalado Graciela Batticuore en su estudio sobre Mariquita Sánchez, la casa constituye un espacio crucial a la hora de entender el mundo ilustrado de la elite porteña de principios de siglo XIX. Foro y escuela de la ciudadanía, la casa es el lugar donde "las personalidades más afamadas de la época" van a "conversar y a aprender, a embeberse de las ideas nuevas del siglo y a celebrar su confianza en el espíritu de las luces" (127).

De hecho, los relatos que narran los orígenes de Pellegrini como retratista remiten al espacio de las reuniones privadas. De acuerdo a su hijo Ernesto, sus actividades artísticas comenzaron en el salón de Mariquita Sánchez, con un retrato de la dueña de casa. El éxito fue inmediato: "Al día siguiente circulaba por todos los salones y era el asunto del día en los círculos sociales” (Pellegrini, Catálogo 5). Por su lado, María Meyer sostiene que Pellegrini se inició como retratista en una cena en la que dibujó el rostro de la anfitriona; el parecido provocó tanto asombro en comensales que pronto llegaron nuevos pedidos para el ingeniero recién llegado a Buenos Aires (Marani 30). Es imposible comprobar la certeza de estas referencias: hay datos que sugieren que Pellegrini podría haber comenzado sus actividades como retratista en Montevideo, durante su breve residencia en la ciudad en 1828, y la ausencia de todo retrato de Mariquita acrecienta la sospecha sobre su factibilidad (Garaño 22). Pero el poderío de estas historias reside menos en su posible veracidad que en el hecho de que efectivamente formen parte de un imaginario que conecta el retrato a la cultura del salón.

En la propia obra de Pellegrini se encuentran, por lo demás, datos concretos sobre el horizonte de recepción de sus trabajos: hay obras con leyendas que indican redes de pertenencia familiar y social. El retrato de Aniceta Villariño tiene en sus manos una tarjeta en la que se lee "Recuerdo a mis hijos" (figura 1). Algo similar ocurre en el retrato de Pedro José Agrelo, amigo de Rivadavia, depuesto por Rosas de su cargo en la Cámara de Justicia. Estas dedicatorias se articulan bajo la figura del retrato como “don" o "regalo", pero también tienen la intención de ser leídas por amigos o conocidos que visitan la casa. Colgados en la sala o el estudio, los retratos consolidan, en este sentido, los límites de la intimidad patricia. Batticuore ha subrayado precisamente que la cultura del salón y de las tertulias están sostenidas en "la dinámica 'familiar' que gobierna los lazos entre los habitués de esta clase de círculos", donde el parentesco "no es necesariamente de tipo biológico sino de corte intelectual (y espiritual)" (Mariquita Sánchez 197-98). Los retratos de Pellegrini cumplen así un rol fundamental en la redefinición de la casa de la elite porteña como un espacio de comunicación de sentidos artísticos. El salón, además del sitio de la tertulia, es el escenario donde se despliega una política visual que acompaña los debates que sostienen los dueños de la residencia y sus allegados.

Revista Iberoamericana, Vol. LXXXII, Núm. 257, Octubre-Diciembre 2016, 721-742 ISSN 0034-9631 (Impreso)

ISSN 2154-4794 (Electrónico) 




Figura 1

En ningún lugar de la obra de Pellegrini se articula de modo más enfático y complejo el proceso de construcción de una ciudadanía posrevolucionaria republicana e ilustrada en el ámbito doméstico que en sus escenas de lectores. Eje de constitución de toda una pedagogía visual ejemplar y edificante, el libro no está directamente asociado en los retratos de Pellegrini a un proceso de subjetivación o internalización cultural, sino a la caracterización de una figura política, social o cultural de la elite porteña: aparece

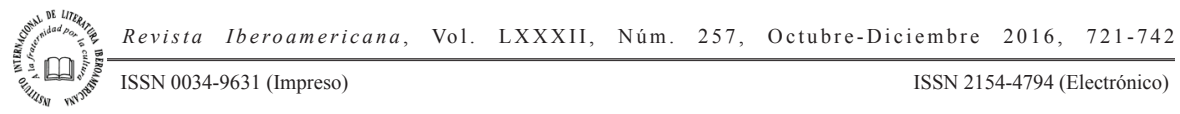


en los estantes de las bibliotecas familiares que constituyen el fondo del retrato, en la mesa de trabajo o en las manos del retratado. En Pellegrini no hay, de hecho, lectores con los ojos puestos en los signos del texto, esto es, lectura concentrada, ensimismada o introspectiva. Por el contrario: sus lectores miran generalmente al observador en el momento de suspensión de la lectura y lo invitan a un diálogo visual. Ojos y libros se dirigen hacia fuera del cuadro: el observador se convierte así en destinatario de una apelación doble. Espacios, gestualidades y textos separan, sin embargo, el modo en que hombres y mujeres se constituyen en lectores en Pellegrini.

En sus retratos con libros, los hombres son presentados usualmente en lugares de la casa diferentes a los ocupados por las mujeres. Así, por ejemplo, Juan Manuel Fernández de Agüero, Narciso Martínez de Hoz, Mariano Medrano y Cabrera, Miguel del Mármol Ibarrola, Bernardino Ocampo, Mariano Torres y Manuel Antonio Castro aparecen sentados en un sillón individual frente a su mesa de trabajo, en el que se perciben libros y textos manuscritos (obras en elaboración, cartas, documentos). Los instrumentos de escritura -el tintero y las plumas- ocupan un lugar prominente. Se trata, por lo demás, de retratos donde el sujeto aparece representado en el momento de una perceptible actividad intelectual. La superposición de volúmenes y papeles, el desorden de libros y manuscritos, sugieren una profusa labor del pensamiento. Por último, son retratos saturados de elementos decorativos. El notorio lujo del mobiliario, visible en la riqueza de las bibliotecas, como en las propias sillas y los cortinados que enmarcan al sujeto retratado, está destinado a subrayar su jerarquía social y cultural. De hecho, aún en los pocos casos en que los lectores no aparecen rodeados de una pesada ornamentación - como es el caso de Agustín José Donado, José Antonio Lagos y Pablo Villarino- estas figuras todavía se presentan frente a una mesa de trabajo que los "separa" del observador. En estas obras, la lectura constituye una actividad ligada a un espacio cerrado y decididamente privado.

El lector y escritor que trabaja en la reclusión de su estudio encuentra su reverso en el caso de las mujeres, donde la posesión y el uso del libro se visualiza en un contexto diferente. En efecto, la representación de la lectora-Secundina de la Iglesia, Feliciana Ugalde, Lucía Carranza, Francisca Ambroa, Isabel Agüero, Aniceta Villarino- está comúnmente ligada al espacio amplio de la sala y a un lugar específico dentro de esa sala: el de un sillón de dos o tres cuerpos en el que ella aparece sentada. Estos detalles refuerzan la idea de la lectura femenina como una práctica que se produce en un lugar destinado, en principio, a compartirse. Esta función de la sala y el sillón está claramente explicitada en el retrato de Secundina de la Iglesia, por ejemplo, que aparece con su hija pequeña, en una escena de lectura dual (figura 2). Por su parte, la falta de una mesa de trabajo que se interponga entre la mujer retratada y el observador también promueve una percepción de una lectora más "accesible". Estos retratos subrayan una cercanía palpable entre personaje y espectador. Si se incluye a veces una mesita baja, ésta funciona como un elemento decorativo secundario y no como marcador de

Revista Iberoamericana, Vol. LXXXII, Núm. 257, Octubre-Diciembre 2016, $721-742$ ISSN 0034-9631 (Impreso)

ISSN 2154-4794 (Electrónico) 
condiciones jerárquicas de poder y saber. En los retratos de lectoras, los elementos decorativos están, por su parte, reducidos al mínimo. Frente a la imagen del letrado rodeado de libros y papeles, la lectora se figura usualmente en un espacio semivacío y ordenado. De hecho, en las representaciones de lectoras aparece con frecuencia una cenefa en la pared, que divide la composición por la mitad, reforzando un sentido de decoro y simplicidad asentado en la simetría.

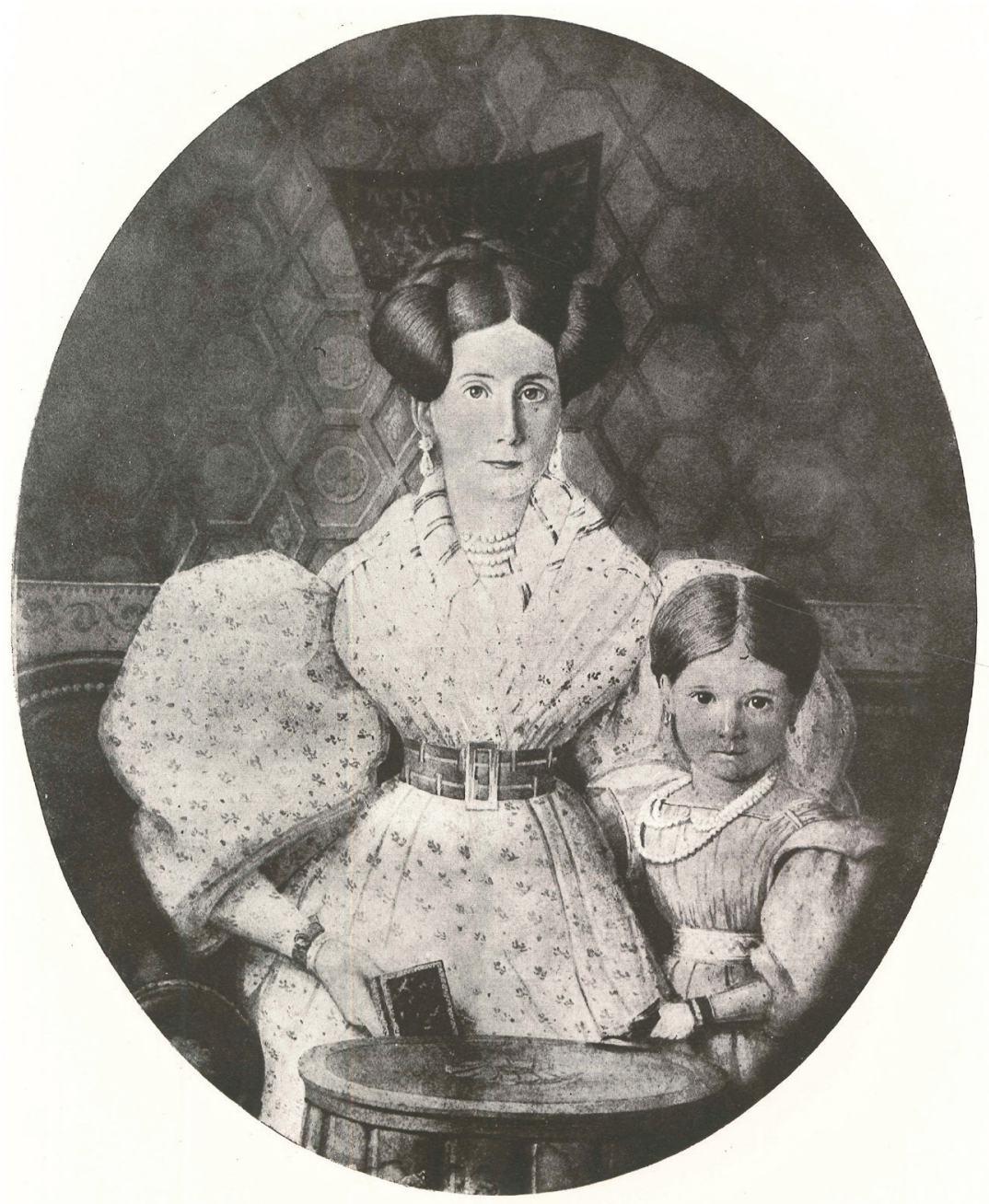

Figura 2

Pevista Iberoamericana, Vol. LXXXII, Núm. 257, Octubre-Diciembre $2016, \quad 721-742$
ISSN 2154-4794 (Electrónico) 
Con respecto al libro mismo, aunque no siempre es posible identificar los títulos de los volúmenes representados en sus obras, dos elementos resultan destacables en los retratos de lectoras: frente a los textos publicados o manuscritos de temas filosóficos, jurídicos o teológicos que ocupan a los hombres, el libro que tienen entre manos las lectoras es siempre de formato pequeño, de contenido didáctico o religioso. Se trata, en todos los casos, de lecturas alejadas de toda función de entretenimiento. De hecho, los retratos de Pellegrini promueven la imagen de un lector culto que excluye el consumo de lo literario en su sentido más moderno. Pellegrini no es un artista por el que podamos observar la lectura de poesía o ficción. En este sentido, la representación de la lectura en Pellegrini es indiferente a las novedades literarias de la época, particularmente a los textos románticos que circulaban ya en 1830: a pesar de su conocimiento de Vernet y de las nuevas ideas, el retratista encuentra todavía en el modelo cultural ilustrado una forma más eficaz de resistencia a la violencia y la censura impuestas por Rosas.

En este contexto, la valoración del libro, la libertad de imprenta y la alfabetización -eje de la política rivadaviana- constituye el marco más inmediato del proyecto estético-ideológico en el que se inscribe la retratística de Pellegrini. La importancia concedida a la cultura del libro y la lectura en la educación de las elites y el pueblo supone, en su obra visual, la coronación de una política cultural implementada desde finales de la colonia y promovida durante el proceso revolucionario, que alcanza su primer momento de realización efectiva en la década de 1820. Como ha señalado Batticuore en "Los libros de la revolución", la idea del libro y la biblioteca adquiere para los partidarios de la Ilustración un valor "emblemático": más allá del acto mismo de leer, la posesión y la difusión de los libros suponen en sí mismas una contribución al “engrandecimiento de la patria" (113), ya que se los percibe como elementos portadores en su propia materialidad de un capital cultural progresista y modernizador: se trata de "una confianza ciega, absoluta, en el poder redentor de los libros" (118).

\section{UNA DIDÁCTICA CRÍTICA: TRES LECTORES}

Viendo amenazado ese proyecto ilustrado con el advenimiento de Rosas al poder, Pellegrini hace de sus retratos un recordatorio permanente de los principios políticos y sociales republicanos así como de los ideales de libertad de expresión y educación cívica. La realización de esta política visual tiene en las escenas de lectura de obras didácticas el punto más explícito de articulación. Tres retratos ejemplifican esta estrategia: los de Juan Manuel Fernández de Agüero, Manuel Antonio Castro y Lucía Carranza de Rodríguez Orey. Capturados mirando a los ojos al observador y con libros didácticos en sus manos, cuyos títulos aparecen claramente visibles, estos personajes llaman la atención sobre la función del libro en la vida pública a comienzos de la década de 1830 .

El retrato deAgüero (figura 3), ejecutado en octubre de 1831, representa al personaje después de su renuncia al cargo de primer profesor de filosofía de la Universidad de

Revista Iberoamericana, Vol. LXXXII, Núm. 257, Octubre-Diciembre 2016, 721-742 ISSN 0034-9631 (Impreso)

ISSN 2154-4794 (Electrónico) 
Buenos Aires, a raíz del cuestionamiento de sus ideas por parte del gobierno federal que siguió a la presidencia de Rivadavia. En efecto, Agüero (1772-1840) había sido la cara de la corriente filosófica sobre la que se había asentado la política rivadaviana desde 1822, primero desde el ministerio de gobierno y luego desde el ejecutivo nacional. $\mathrm{Si}$ bien en su juventud se había volcado a diversas actividades relativas a su formación sacerdotal -se desempeñó como docente de filosofía escolástica en el Colegio de San Carlos entre 1805 y 1807, fue Capellán Real desde 1806 y cura de Morón entre 1808 y 1813- Agüero llevaba diez años alejado de la vida pública cuando Rivadavia, su antiguo compañero de estudios secundarios, lo convocó en 1822 a enseñar Ideología en la recién fundada Universidad de Buenos Aires. Nacido en España, los diez años que pasó excluido de cargos religiosos a raíz de la prohibición de trabajar a los extranjeros, impuesta por la Asamblea del Año 1813, fueron decisivos para que Agüero desarrollara un fuerte interés por la filosofía racionalista que lo llevaría a cuestionar decididamente el dogmatismo escolástico.

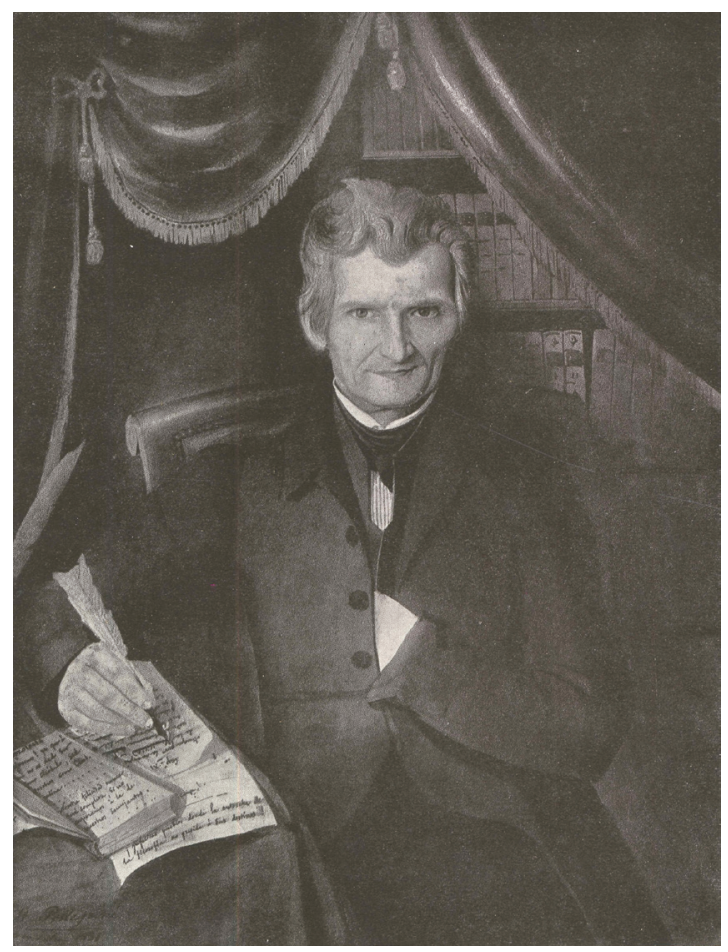

Figura 3

Revista Iberoamericana, Vol. LXXXII, Núm. 257, Octubre-Diciembre 2016, $721-742$ 
La radicalidad de sus ideas filosóficas en el medio local se hizo, de hecho, inmediatamente transparente al asumir la cátedra universitaria. El curso que comenzó a impartir en Buenos Aires en 1822 comprendió la enseñanza de lógica, metafísica y retórica según una única perspectiva: la de la Ideología francesa del siglo XVIII. Fue la singularidad de esta aproximación lo que provocó una reacción adversa en el medio universitario, eclesiástico y social de Buenos Aires. El propio rector de la Universidad, Antonio Sánchez, encabezó la lista de los sectores del gobierno y de la curia que calificaron sus lecciones de impías, por lo cual dictó en 1824 una orden que le impedía a Agüero ingresar a su aula. Repuesto en su cargo por Rivadavia -en tanto su nombramiento dependía del gobierno y no del rector-, sus actividades como docente de filosofía cesaron por fin en 1827, cuando ya depuestas las autoridades unitarias, el nuevo gobierno insistió que su enseñanza era "perjudicial a la causa pública"(Fernández de Agüero 243).

El retrato de Pellegrini captura a Agüero tres años después de su exclusión de la cátedra de Ideología, con lo que Schiaffino describió como un "rictus sardónico" (36) en el rostro. Escribiendo sobre su mesa de trabajo, rodeado por su biblioteca, Agüero es retratado junto al libro que había sido la causa decisiva de la polémica y final condena de su actuación universitaria: los Principios de Ideología, texto didáctico compuesto para sus estudiantes universitarios. Para rematar la intención crítica del retrato, Pellegrini presenta el texto virado hacia el observador, abierto en su primera página, donde cuestiona el dogmatismo religioso, y encima de una hoja de papel en la que se puede leer una frase manuscrita que destaca la importancia de la filosofía a la hora de "presidir" el "destino" de los "pueblos". Todos estos elementos sugieren que Pellegrini hizo de Agüero el sujeto de una obra decididamente politizada, por la cual se respalda la gestión de Rivadavia a través de la figura del docente que había representado su pensamiento universitario en la vida pública.

De hecho, lo que manifiesta el carácter desafiante y reivindicador de la imagen de Agüero por parte de Pellegrini no es sólo que el retrato introduzca su Ideología, sino que la presente en su versión manuscrita, aunque la obra circulaba impresa desde mediados de la década de 1820 . Fue, de hecho, la existencia de más de cuarenta copias del texto de Agüero reproducidas por los alumnos del curso de 1823 lo que desató las primeras reacciones adversas a su labor docente entre los sectores más conservadores. Jorge Zamudio ha escrito que el origen de las acusaciones contra el catedrático se produjeron precisamente cuando "esos papeles llegaron a poder del vicario capitular" quien afirmó que lo que había "leído en sus cuadernos eran proposiciones escandalosas y heréticas" (26), después de lo cual se inició la ofensiva del rector y de la Iglesia.

En el retrato de Pellegrini la Ideología de Agüero opera como una apuesta en favor del racionalismo ilustrado y en oposición a la escolástica filosófica. Si durante la época de Rivadavia la defensa de Agüero por parte del gobierno había señalado un hito en el posicionamiento oficial sobre el lugar de la Iglesia católica en la vida

Revista Iberoamericana, Vol. LXXXII, Núm. 257, Octubre-Diciembre 2016, $721-742$ ISSN 0034-9631 (Impreso)

ISSN 2154-4794 (Electrónico) 
política y social -central para el proyecto de estado pero alejada de su ortodoxia- en 1831, fecha del retrato, la obra de Agüero servía doblemente como defensa del rol de las luces y el libro frente a un gobierno que otra vez las cuestionaba. Aunque no se sabe que Agüero haya ejercido el sacerdocio después de 1813, el hecho de que aparezca vestido de sotana junto a su texto antiescolástico subraya la noción de un clero funcional al estado y adaptado a los ideales de la modernización. En efecto, a pesar de ser adversario del dogmatismo teológico, Agüero en ningún punto de su carrera abogó por la separación del catolicismo de la esfera gubernamental. Favorecía, de hecho, un proceso de secularización eclesiástica en que la institución, desprendida de Roma, adquiría funciones sociales: para él, la iglesia debía ser un órgano sometido al gobierno.

El retrato del jurisconsulto, publicista y político Manuel Antonio Castro (figura 4), ejecutado también en 1831, presenta significativas continuidades con el de Agüero: Pellegrini retrata a Castro (1772-1832) en su estudio, rodeado de una amplia biblioteca y frente a una mesa de trabajo en la que destacan instrumentos

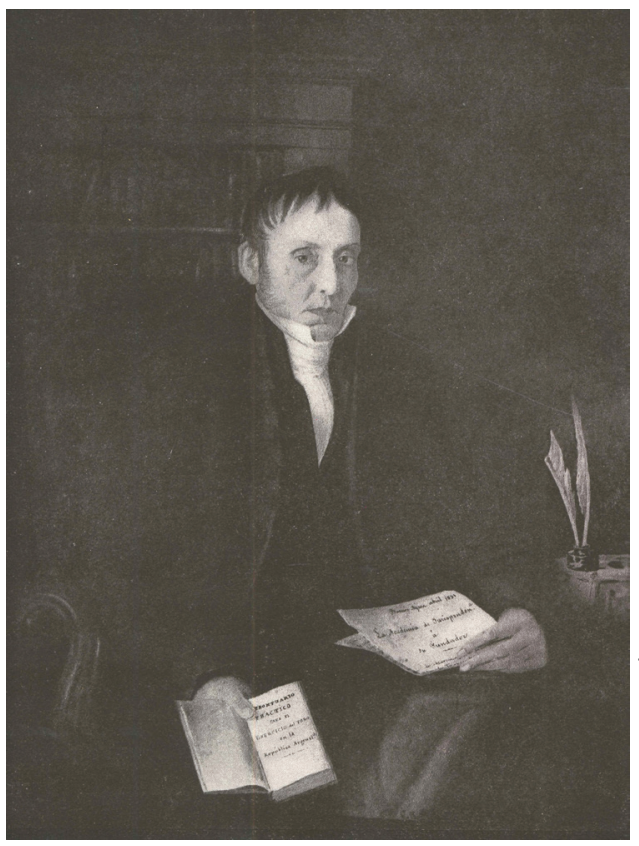
de escritura. Otra vez se subraya aquí la apuesta por un tipo específico de visualidad didáctica que se inscribe tanto en la propia gestualidad del retratado como en el género mismo de los materiales que muestra. Castro sostiene en sus manos dos textos que aparecen dibujados en dirección al observador y como avanzando en su dirección: su obra didáctica manuscrita, Prontuario práctico para el ejercicio del foro en la República Argentina (que será publicada después de su muerte bajo el título de Prontuario de práctica forense), y una carta-diploma, también manuscrita, donde se lee la frase: "La Academia de Jurisprudencia a su fundador".

\section{Figura 4}

Se trata, sin duda, de un retrato legitimante de la trayectoria intelectual de Castro. Si bien había sido un publicista prolífico, Pellegrini prefiere retratarlo, sin embargo, como autor de una obra "destinada a la enseñanza de la juventud americana",

\footnotetext{
ISSN 2154-4794 (Electrónico)
ISSN 0034-9631 (Impreso)
} 
todavía inconclusa en ese momento, que escribió para los alumnos de la Academia de Jurisprudencia, entidad de la que había sido fundador y director vitalicio (Levene xvi). Estos elementos son decisivos para entender la versión de Castro que propone Pellegrini. Firme realista en el momento de estallar la Revolución de Mayo (lo que provocó su encarcelamiento preventivo, dictado por Mariano Moreno), Castro pasó a convertirse en un ferviente unitario en los años 1810 y 1820. Como tal, se desempeñó como Gobernador de Córdoba entre 1817 y 1820, posición desde la cual introdujo reformas en el plan de estudios de la universidad y fundó la biblioteca pública de la ciudad. Desplazado por los federales del gobierno provincial, se instaló en Buenos Aires, donde fue presidente de la Cámara de Justicia así como del Congreso Nacional que dictó la Constitución en 1826. Pero ningún detalle de la biografía de Castro como funcionario surge en la representación de Pellegrini: como en el retrato de Agüero, Pellegrini enfatiza aquí una versión del personaje como constructor intelectual e institucional ligado a una actividad educativa que contaba con fuerte apoyo rivadaviano.

Por último, el retrato de Lucía Carranza (figura 5) también se ubica dentro de este paradigma representacional, pero aparecen en él rasgos decisivos que permiten determinar el rol diferencial que Pellegrini otorgaba a la mujer letrada en su crítica del primer período rosista. En efecto, a diferencia de Agüero y Castro, cuyos retratos los presentan en sus despachos junto a sus propias obras manuscritas, Carranza se ve aquí sentada en una sala sosteniendo en su falda un libro ajeno, que la lectora dirige a sí misma, aunque su título aparece claramente visible al observador: Las aventuras de Telémaco (1699) de François de Fénelon, obispo de Cambray. Este conjunto de detalles no son menores a la hora de entender las funciones de los retratos de lectoras en Pellegrini: frente a la unidireccionalidad didáctica de los dibujos de Agüero y Castro, Carranza asume aquí el rol de la dama ilustrada que, como lectora, al mismo tiempo se cultiva y estimula el cultivo del público.

Figura 5

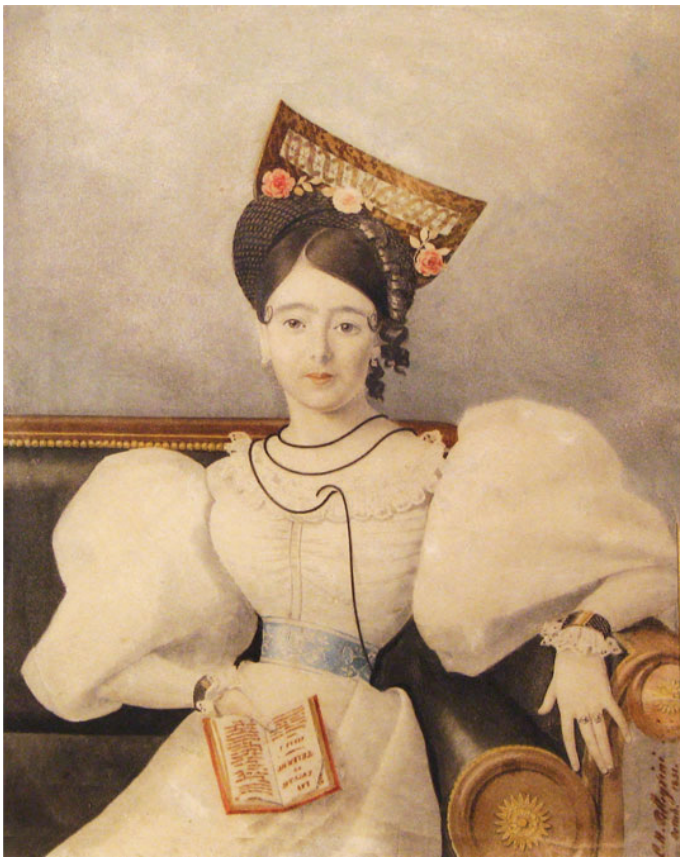

ISSN 2154-4794 (Electrónico)
IST 
La importancia de obra de Fenelón no puede ser descartada a la hora de entender la dimensión ideológica que construye el retrato. Las aventuras de Telémaco fue leído desde el momento de su publicación como una sátira al gobierno autocrático de Luis XIV y, más generalmente, de todo gobierno autocrático. Como los libros de Agüero y de Castro, el libro también era un texto didáctico; como Agüero, también, su autor era un prelado barrido de los círculos oficiales por el régimen vigente. Con un protagonista "nominal" (Telémaco) y un héroe "verdadero" (Mentor, una encarnación de Minerva, la diosa de la sabiduría), Las aventuras de Telémaco es un texto de educación aristocrática en que un docente viejo aparece como influencia cívica y moral superior que orienta y protege al educando. El libro es, por eso, prosa didáctica, emparentada con los manuales de formación de príncipes. A partir de preceptos explicitados en largos parlamentos, Mentor guía a Telémaco en la valoración del amor desinteresado, la amistad y la virtud cívica, opuesta a la política absolutista.

El carácter controvertido de Las aventuras de Telémaco lo hizo inmediatamente exitoso: el público lo abordó como una sátira o roman à clef de la vida de la corte. Detenida su impresión en Francia por orden real antes de que los editores pudieran completar el libro, terminó siendo editado en La Haya sin el nombre del autor. En 1697 Fénelon ya había sido exiliado temporariamente por la casa real debido a su involucramiento en el Quietismo religioso; la publicación de esta obra hizo que su expulsión de Versalles y exilio en la diócesis de Cambray se hiciera permanente. Las aventuras de Telémaco tuvo dieciséis ediciones el año mismo de su publicación, y es considerado el texto con mayor número de reimpresiones en Francia en el siglo XVIII, después de la Biblia. Su influencia fue notoria en pensadores tales como Montesquieu, Prévost, Voltaire y Rousseau. Por su retorno idílico a la naturaleza, manifiesta en sus discursos utópicos, influenció además a Saint Pierre y Chateaubriand. Para el año en que Pellegrini retrató a Carranza, se habían impreso ciento cincuenta ediciones en Francia, existían numerosas imitaciones de toda índole y circulaban más de ochenta traducciones. Las traducciones e imitaciones también proliferaron en América. En español, para 1831, fecha del retrato de Carranza, habían circulado seis ediciones del mismo formato que se ve en la obra de Pellegrini y existían también imitaciones, como la publicada en Perú a comienzos del siglo XVIII (Burucúa 160-61).

Dedicada a la educación del Duque de Borgoña, nieto de Luis XIV y su sucesor aparente, del que Fénelon era tutor, el Las aventuras de Telémaco introducía regímenes políticos alternativos que podían ser leídos como cuestionamientos a la monarquía vigente: por un lado, una Bética comunitaria, pacífica, agraria, austera, con componentes arcádicos y, por otro, el reino de Salento, condensación de monarquismo con virtudes republicanas, que representaba un contraste notorio con la política y la moralidad de Luis XIV. Fénelon atacaba el lujo y advertía sobre los ministros corruptos, las ambiciones imperiales y la belicosidad desmedida; por oposición, subrayaba las virtudes de moderación, honestidad y benevolencia, poniendo especial énfasis en el elogio de

Revista Iberoamericana, Vol. LXXXII, Núm. 257, Octubre-Diciembre 2016, $721-742$ ISSN 0034-9631 (Impreso)

ISSN 2154-4794 (Electrónico) 
la simplicidad. El eje polémico del libro residía particularmente en las instrucciones políticas, sociales y económicas que Mentor daba a Idomeneo, gobernante de Salento, al que proponía organizar el país sobre la base de grupos de familias rurales carentes de ambición. Otras secciones del libro le permitían a Telémaco observar monarcas tiránicos, negligentes y egoístas. En sus largas consideraciones sobre el poder real y el absolutismo, Fénelon defendía la idea de que la autoridad del rey debía asentarse en el respeto por la ley y el sacrificio de su propia libertad en favor del bien común. Según Patrick Reley, leído desde la filosofía política, Las aventuras de Telémaco es un libro sobre el gobierno desinteresado que "sale de sí" para volcarse a la polis (Fénelon, Telemachus xxii-xxiii).

Pero si el retrato de Carranza podía interpretarse como una crítica al régimen rosista desde la perspectiva rivadaviana, tampoco podía dejar de leerse como un libro que daba un rol particular a la mujer en el orden civil. En este sentido, un análisis de la obra de Pellegrini permite afirmar que, de hecho, el artista participaba de las concepciones fenelonianas en torno a la cuestión de la mujer, que el pensador francés había sostenido sin cambios fundamentales desde la escritura de La educación de las niñas. Se trataba, en cualquier caso, de una filosofía que destacaba el carácter decisivo, aunque claramente subordinado, de la mujer en términos políticos y sociales. En Las aventuras de Telémaco, Fénelon reflexionaba sobre el lugar de la mujer a través de los personajes de Calipso y Eucaris, que se presentaban como el opuesto simbólico de Antíope, la hija de Idomeneo, en quien Telémaco veía una mujer digna del futuro soberano. Enemigo del artificio y la vanidad en el vestir y la decoración, Fénelon insistía en este libro que la moda sólo podía producir costumbres desordenadas. Fénelon recomendaba, en este caso, una vuelta a los ideales de simpleza del mundo antiguo, así como a las conductas virtuosas de la ética cristiana. "El catálogo de las virtudes femeninas expuestas en Telémaco recuerdan al lector", según Davis, "las páginas de La educación de las niñas donde Fénelon destaca la modestia, industriosidad, eficiencia doméstica, simpleza en el vestido y ornamentación de la mujer, así como su temperamento amigable". La elección de Antíope sobre la apasionada Calipso sugería además que "la razón ha prevalecido sobre el sentimiento" (101, mi traducción).

En lo que respecta a la vida pública, el rol de la mujer aparece en Fénelon fundamentalmente ligado al servicio social. En particular, insiste en enseñarles cómo establecer escuelas y organizaciones caritativas y de beneficencia, destinadas a brindar ayuda a los pobres y enfermos. Este tema es, de hecho, central en los retratos femeninos de Pellegrini. El énfasis en la cuestión de la caridad surge claramente en el retrato de Pastora Botet, por ejemplo (figura 6). La retratada sostiene un libro cerrado cuya inscripción señala, menos como como título que como leyenda alegórica, la palabra "Beneficencia". La disposición diagonal de la inscripción resalta la importancia didáctica de la pieza, que le recuerda al observador sus deberes públicos. Aunque aparentemente distante de la crítica política que propone Las aventuras de Telémaco, la representación

Revista Iberoamericana, Vol. LXXXII, Núm. 257, Octubre-Diciembre 2016, $721-742$ ISSN 0034-9631 (Impreso)

ISSN 2154-4794 (Electrónico) 
de la lectura orientada a las obras de caridad se alinea perfectamente con los ideales del gobierno de Rivadavia, que en 1823 estableció la Sociedad de Beneficencia para poner bajo la órbita oficial la educación de las niñas y la atención de los pobres. ${ }^{3}$

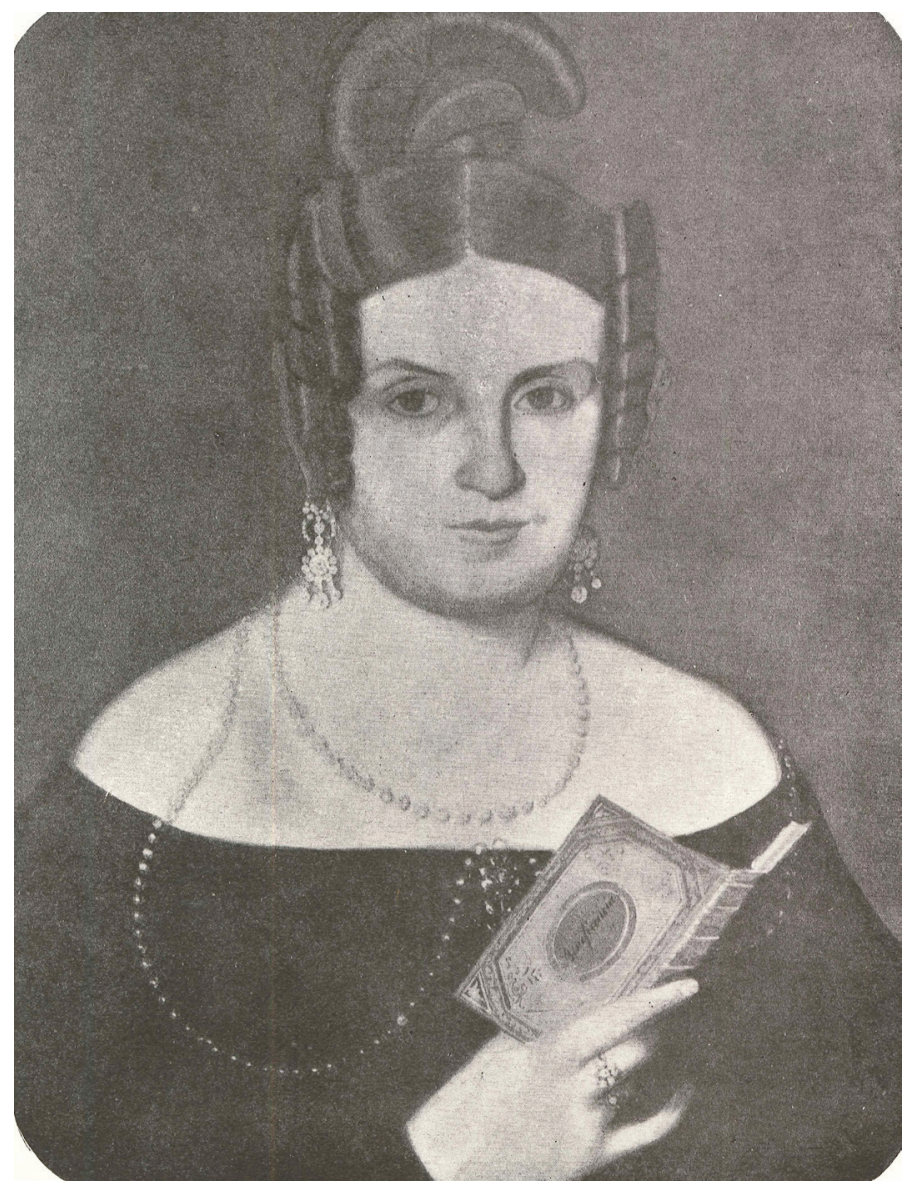

Figura 6

3 Otros dos retratos de Pellegrini están conectados a la Sociedad de Beneficencia rivadaviana: los de José Valentín Gómez e Isabel Agüero de Ugalde. El primero, maestro y amigo de Rivadavia, redactó los reglamentos de la Sociedad de Beneficencia, y fue víctima de los ataques que sufrieron las familias unitarias a comienzos de la década de 1830. La segunda fue una de las integrantes más activas de la organización.

ISevista Iberoamericana, Vol. LXXXII, Núm. 257,
ISctubre-Diciembre 2154-4794 (Electrónico) 
La obra de Fénelon sitúa así a la mujer lectora en posición de crítica y mediadora del orden social. Si Carranza no es, como Agüero y Castro, la autora de libros en los que articula un sistema filosófico e institucional alternativo al vigente, se propone en cambio como una lectora que invita a los espectadores a consolidar un modelo político y de género ligado a ideales iluministas de fundamento cristiano. Colgado en la sala, el retrato de Carranza opera como el de una Mentora: ella misma es espejo de príncipes y texto de formación para sus observadores.

\section{El LUGAR DE LAS PASIONES}

En 1853, después de la caída de Rosas y ya consolidado el romanticismo, Pellegrini funda en Buenos Aires la Revista del Plata. Valiéndose en esta ocasión de la escritura como medio de intervención cultural en la sociedad de su tiempo, Pellegrini explicita allí algunas ideas claves para entender sus retratos. En el prospecto de la publicación, Pellegrini señala que frente a la carencia de educación científica, esencial para cualquier "empresa económica de magnitud", es necesario promover "el desarrollo de los poderes productivos del país" (Marani 73). Pero en esta renovada apuesta por poner el conocimiento al servicio del liberalismo político y económico aparece también un tema decisivo: el del rol de las pasiones en la construcción de la sociedad civil. Contra los críticos de su Revista, que señalaban que era imprescindible pacificar el país antes de lanzarse a realizar un proyecto de esa envergadura, Pellegrini señala que está "persuadido" de que "atraer los ánimos sobre un cuadro de realidades útiles es distraerlos provechosamente, es aquietar las pasiones" (73). Se trataba de una idea que estaba en consonancia con los "principios" de un código de conducta según el cual el "principal recreo del hombre" lo constituye la "ocupación de la inteligencia" y lo importante en la vida cotidiana es "evitar todos los excesos" (91).

De hecho, el tema de la moderación política había estado presente en la producción artística de Pellegrini en la década de 1830. Valiéndose de la escritura, había introducido este concepto en uno de los pocos retratos oficiales que produjo por entonces: el tríptico donde muestra a Juan J. Viamonte como gobernador de Buenos Aires junto a sus ministros Manuel J. García y Tomás Guido, realizado en 1834 entre el primer y el segundo gobierno de Rosas. Celebrando los esfuerzos de Viamonte por conciliar las facciones federales y asegurar la estabilidad de la provincia, Pellegrini incorpora al retrato una leyenda en la que expresa su adhesión a la política del gobernador en estos términos: "Ó modération, tu as été et tu seras la gardienne éternelle de tout". Se trataba de un modo de pensar el futuro del país que compartirían otros miembros de la elite después de la derrota de Rosas. Volviendo al tema de la conexión entre política, economía y emociones, el propio Tomás Guido le decía a Pellegrini en una carta enviada al año siguiente de la fundación de la Revista del Plata: "No está perdida la esperanza para la Patria, cuando en medio de las pasiones excitadas todavía por la lucha

Revista Iberoamericana, Vol. LXXXII, Núm. 257, Octubre-Diciembre 2016, $721-742$ ISSN 0034-9631 (Impreso)

ISSN 2154-4794 (Electrónico) 
reciente se levanta una voz ilustrada y amiga, llamando a mis conciudadanos al campo del trabajo y de la riqueza, y mostrándoles la única fuente segura de prosperidad y de progreso". Este "sacerdocio de la paz y de la instrucción útil" (75), como lo calificaba el propio Guido, estaba relacionado, también para él, con la producción de un orden social en el que la regulación de los sentimientos debía ser una problemática central.

A pesar de estas formulaciones, resulta evidente que Pellegrini no se encontraba, sin embargo, entre los defensores de la contención a ultranza de las pasiones desatadas por el rosismo. Un romántico de tendencias ilustradas como Juan M. Gutiérrez, preocupado por la dirección política y social de un país sometido a ciclos de violencia y anarquía, llegó a criticar la revista de Pellegrini porque estaba demasiado comprometida con los asuntos del presente. En una carta en que discutía el carácter de la publicación, Gutiérrez le proponía a Pellegrini que censurara, aún con más rigor, cualquier elemento de la revista que "sublevara ideas encontradas", sobre todo en materia política. Así, por ejemplo, le decía que se abstuviera de divulgar biografías de hombres contemporáneos ya que podían desatar conflictos de opinión, y le sugería que se ocupara en su lugar de muertos, "porque éstos ya no inspiran ni sublevan pasiones" (76).

El tema de la biografía de personalidades ilustres no era menor en este contexto: desde sus años como retratista, Pellegrini había sido precisamente el biógrafo visual de la elite porteña, y la opinión de Gutiérrez podía aplicarse en ese sentido a las representaciones visuales de Pellegrini. En efecto, así como no había sido capaz de suprimir en las biografías de su revista posiciones controvertidas, tampoco sus retratos de principios de la década de 1830 podían ser interpretados como obras despojadas de expresiones de afectividad a través de las cuales se juzgaban, de forma abierta y marcada, circunstancias políticas contemporáneas y por medio de las cuales se esperaba producir "ideas encontradas".

Aunque partidario del "lenguaje poco prestigioso, pero benéfico, de la razón calculadora e inventiva" (75), resulta innegable que Pellegrini percibía la productividad que tenía la canalización de las pasiones. Su justificación se basaba, sin duda, en una valoración de la idea de "latinidad", que venían elaborando por entonces algunos ministros franceses del Segundo Imperio y sus allegados hispanoamericanos frente a la expansión imperial anglosajona (Degiovanni 351-68). Conocedor de esos discursos, Pellegrini escribía que, si bien después de la "larga época de destrucción y barbarie" representada por el rosismo, era difícil encaminar el "carácter de la raza latina", reconocía que en ella no todo era negativo: "más sentimental que especulativa", el hecho de que la raza latina fuera "tan fogosa en sus raptos de cordura como en sus extravíos, tan expresiva, tan amante de lo bello y de los placeres, explicaba esta singularidad" (82). Algunos de sus retratos de lectores, como los de Agüero y Carranza, demuestran precisamente hasta dónde lo que Pellegrini entendía como rasgos de la "latinidad" podía servir no para alimentar el desorden social, sino para estimular un discurso crítico.

Revista Iberoamericana, Vol. LXXXII, Núm. 257, Octubre-Diciembre 2016, $721-742$ ISSN 0034-9631 (Impreso) 
Los rostros de sus personajes ilustrados articulan claramente su posición frente al tema. Garrett Stewart ha escrito que "the figure of textual attention is able to invoke [... the invisible somatic and affective motions of the organic body in reading" (77). La comparación entre rostro y torso es esencial para comprender esta dinámica en Pellegrini. Resulta evidente que la representación del cuerpo adquiere rasgos formuladores en sus obras: además de la rigidez de sus poses, los retratados aparecen caracterizados en general de manera pasiva. La gran mayoría de ellos se encuentran sentados y la falta de gestualidad corporal sugiere una idea de estatismo y autocontención. Pero el rostro, y en menor medida las manos, ofrecen un contraste a la fijeza de los cuerpos. West ha señalado que desde el Renacimiento las teorías del retrato prestaron especial atención a la relación entre el cuerpo y la cara, entendida como traducción del alma y la mente. Precisamente los sistemas por los cuales el carácter podía ser deducido a través del rostro del retratado adquirieron renovada popularidad durante la Ilustración. Las expresiones faciales fueron codificadas entonces en relación con las pasiones (Woodall 6).

La “expresión”, en cuanto manifestación de los efectos emocionales temporarios en el rostro, adquiere un lugar crucial en los retratos de Agüero y Carranza. El rostro de Agüero quizás sea el más destacado desde esta perspectiva, puesto que la mueca que le dibuja Pellegrini rompe las convenciones que regían la composición de retratos de personas de autoridad social, y constituye un rasgo extraordinario. West ha señalado que hasta el siglo XX fue "uncommon for portraits to show any extreme expression, as neutral and studied features gave sitters an air of dignified repose or concentration" (34). El hecho de que Pellegrini haya decidido incorporar este gesto inusual y problemático para la tradición retratística sugiere una deliberada intención de mostrar la función crítica de las emociones en su obra. Por otra parte, el "rictus sardónico" de Agüero (36), como lo llama Schiaffino, cobra particular relieve porque aparece sobre un fondo que tiende a resaltar el carácter grave del despacho de Agüero, saturado de pesados cortinados y libros de gran formato. Única, por su parte, en la obra de Pellegrini, la mueca de Agüero acompaña así a sus propios textos en la desaprobación de la situación política vigente.

Las manos de Agüero también aportan algunos elementos interpretativos en este contexto. Mientras su mano derecha sostiene la pluma, la izquierda está metida en la sotana, sobre su pecho. Si bien ocultar las manos ha sido un recurso usado con frecuencia por los artistas para evitar dibujarlas -sobre todo entre los menos talentosos- éste no parece ser el caso en Pellegrini, que las incluye repetidamente en sus obras. Así, debe entenderse que el detalle cumple una función deliberada en la construcción del retrato de Agüero: a diferencia de la clásica postura napoleónica de cruzar la mano justo en medio del chaleco -común a muchos retratos del siglo XVIII-, la mano oculta de Agüero se dirige hacia arriba, asentándose cerca del corazón. Es esa localización excepcional la que invita a pensar, como su propia mueca, en el valor simbólico adicional del gesto,

Revista Iberoamericana, Vol. LXXXII, Núm. 257, Octubre-Diciembre 2016, 721-742 ISSN 0034-9631 (Impreso)

ISSN 2154-4794 (Electrónico) 
asociado a la expresión de la honestidad intelectual o afectiva. La mueca del rostro y la dirección de la mano se combinan para subrayar, por consiguiente, dos sentimientos complementarios -escepticismo y sinceramiento- de una manera sutil pero efectiva.

En el caso de Carranza, la cara de sorpresa de la lectora es uno de los rasgos más notorios de un retrato en que el torso aparece dibujado, por su parte, de manera absolutamente frontal. Según West, la tendencia a presentar las figuras de manera frontal y centrada se relaciona, en la historia del retrato, con la idea de fuerza y poder, ligadas a la autoridad (73). En este sentido, podría decirse que en contraste con la posición de autoridad del cuerpo, Carranza muestra su costado "vulnerable" al ser capturada leyendo por un intruso que parece haber llegado a la sala de repente y sin llamar. Hay incluso la posibilidad de observar cierto desconcierto en el rostro: en la suspensión de esa mirada que ha interrumpido la lectura, Carranza se percibe algo incómoda e insegura. Es evidente, por lo demás, que comparada a las numerosas mujeres retratadas por Pellegrini, Carranza presenta aquí una gestualidad menos asertiva que la de las otras damas de la elite. Capturada por el retratista en el momento en que lee un libro crítico del poder autocrático, ella encarna el símbolo de la disidencia que tiene lugar en las lecturas del salón. Por su parte, la mano izquierda, que se ve cargada de joyas y aparece quebrada deliberadamente hacia el espectador en un gesto forzado, tiene como propósito subrayar el equilibrio entre erudición y belleza, rasgo común en la representación visual de la mujer ilustrada, como puede verse en los numerosos retratos de Madame de Pompadour y Madame Recamier.

Alejado de cualquier apuesta por la pasión desbocada-que, además de los neoclásicos, también puede registrarse en algunos románticos argentinos, contemporáneos suyosPellegrini ofrece de este modo una lección de política y cultura anclada en el diálogo entre cuerpos y textos: sus lectores de libros didácticos buscan promover una disonancia ideológica en el marco de las batallas por la ciudadanía. En estos retratos se juegan, de hecho, algunas de las posibilidades y límites de la representación de la cognición y la pasión en la historia temprana de las ideas en Argentina.

\section{BibLIOGRAFía}

Batticuore, Graciela. "Los libros de la revolución". Tres momentos de la cultura argentina: 1810-1910-2010. Graciela Batticuore y Sandra Gayol, eds. Buenos Aires: Prometeo, 2011. 103-26.

Mariquita Sánchez: bajo el signo de la revolución. Buenos Aires, Edhasa, 2011.

Beyer, Andreas. Portraits: A History. New York: Harry Abrams, 2003.

Brilliant, Richard. Portraiture. Cambridge: Harvard UP, 1991.

Burucúa, José Emilio. Historia y ambivalencia: ensayos sobre arte. Buenos Aires:

Biblos, 2006.

Revista Iberoamericana, Vol. LXXXII, Núm. 257, Octubre-Diciembre 2016, $721-742$ ISSN 0034-9631 (Impreso)

ISSN 2154-4794 (Electrónico) 
Castro, Manuel Antonio de. Prontuario de práctica forense. Ricardo Levene, ed. Buenos Aires: Facultad de Derecho y Ciencias Sociales, 1945.

Clark, Priscilla. "The Metamorphosis of Mentor: Fénelon to Balzac." Romanic Review 75 (1984): 200-15.

Davis, James Herbert. Fénelon. Boston: Twayne, 1979.

Degiovanni, Fernando. "Shifting Hegemonies: The Cultural Politics of Empire." $A$ Companion to Latin American Literature and Culture. Sara Castro-Klaren, ed. Oxford: Blackwell, 2008. 351-68.

Fénelon, François de. The Adventures of Telemachus, the Son of Ulysses. Leslie A. Chilton, ed. Athens: The U of Georgia P, 1997.

Telemachus, Son of Ulysses. Patrick Riley, ed. New York: Cambridge UP, 1994.

Fernández de Agüero, Juan Manuel. Principios de Ideología: elemental, abstractiva y oratoria. Jorge Zamudio Silva, ed. Buenos Aires: Facultad de Filosofía y Letras, 1940.

Garaño, Alejo González. Prólogo. Su obra, su vida, su tiempo. Alejo González Garaño, ed. Buenos Aires: Amigos del Arte, 1946. 11-29.

Gross, Sabine. "Reading in Style: Visual Text from a New Angle." Poetics Today 29 (2008): 565-93.

Levene, Ricardo. Noticia preliminar. Prontuario de práctica forense. Ricardo Levene, ed. Buenos Aires: Facultad de Derecho y Ciencias Sociales, 1945. xv-xxii.

Lynch, John. Argentine Dictator Juan Manuel de Rosas, 1829-1852. Oxford: Clarendon Press, 1981.

MacClintock, Lucy M. Romantic "Actualité": Contemporaneity and Execution in the Work of Delacroix, Vernet, Scheffer and Sigalon. Tesis de doctorado. Harvard University, 1993.

Mansilla, Lucio V. Mis memorias. Buenos Aires: EUDEBA, 1966.

Marani, Alma Novella. Carlos E. Pellegrini: De la Torino de 1821 a la Buenos Aires de los caudillos. Roma: Bulzoni, 1988.

Parada, Alejandro E. El mundo del libro y de la lectura durante la época de Rivadavia: una aproximación a través de los avisos de La Gaceta Mercantil (1823-1828). Buenos Aires: Universidad de Buenos Aires, 1998.

Pellegrini, Charles Henri. Catálogo: Exposición de retratos, paisajes y otros grabados ... reunidos en ocasión de su centenario. Buenos Aires: Compañía Sud-Americana de Billetes de Banco, 1900.

Su obra, su vida, su tiempo. Alejo González Garaño, ed. Buenos Aires: Amigos del Arte, 1946.

Pope-Hennessy, John. The Portrait in the Renaissance. New York: Bollingen Foundation/ Pantheon Books, 1966.

Ribera, Adolfo Luis. El retrato en Buenos Aires 1580-1870. Buenos Aires: Universidad

Revista Iberoamericana, Vol. LXXXII, Núm. 257, Octubre-Diciembre 2016, 721-742 
de Buenos Aires, 1982.

Schiaffino, Eduardo. La evolución del gusto artístico en Buenos Aires. Godofredo Canale, ed. Buenos Aires: Francisco A. Colombo, 1982.

Soussloff, Catherine M. Portraiture and the Birth of the Modern. Durham: Duke UP, 2006.

Stewart, Garrett. The Look of Reading: Book, Painting, Text. Chicago: U of Chicago P, 2006.

West, Shearer. Portraiture. Oxford: Oxford UP, 2004.

Woodall, Joanna, ed. Portraiture: Facing the Subject. Manchester: ManchesterUP, 1997. 